\title{
Desterritorialización en políticas de vivienda. El caso de la Ley No 6.758/05: Programa Provincial de Vivienda Rural de Santiago del Estero (Argentina)
}

\author{
Joaquín Ezequiel Olivarez ${ }^{1}$ \\ Universidad Nacional de Santiago del Estero \\ Consejo Nacional de Investigaciones Científicas y Técnicas \\ @ [ joaquinolivarez.arq@gmail.com ]
}

\section{Guillermo Rolón²}

Universidad Nacional de Tucumán / Consejo Nacional de Investigaciones Científicas y Técnicas

@ [ guillerolon02@gmail.com ]

RECIBIDO 30-06-2021

ACEPTADO 14-08-2021

Cita sugerida:. Olivarez, J. E. y Rolón, G. (2021). Desterritorialización en políticas de vivienda. El caso de la Ley $N^{\circ}$ 6.758/05: Programa Provincial de Vivienda Rural de Santiago del Estero (Argentina). Revista Huellas, Volumen 25, № 2, Instituto de Geografía, EdUNLPam: Santa Rosa. Recuperado a partir de: http://cerac.unlpam.edu.ar/index.php/huellas

DOI: http://dx.doi.org/10.19137/huellas-2021-2524

\section{Resumen}

El estado, en el marco de una estrategia de desarrollo frente al riesgo y la vulnerabilidad que implican el déficit habitacional, promueve políticas de vivienda que inciden en la transformación del espacio y en la configuración de las territorialidades de la población. Sin embargo, las prácticas y representaciones estatales sobre las problemáticas del hábitat responden al grado de hegemonía que ejerce, imponiéndose sobre las condiciones locales del hábitat y los marcos socio-culturales. En tal sentido, el trabajo analiza la lógica de territorialización derivada de las conceptualizaciones implicadas en la Ley provincial $\mathrm{N}^{\circ}$ $6.758 / 05$, declarada para la producción de viviendas rurales en la provincia de Santiago del Estero. Para ello, este trabajo hizo hincapié sobre cuatro ejes: la delimitación del problema/solución habitacional, las directivas respecto al proceso de ejecución de la política, los destinatarios y la solución habitacional. Se observó que la política de vivienda rural basada en esta Ley, incidiría en el espacio implicando un proceso de desterritorialización por la modificación de las características del sistema de habitar previo y otro de reterritorialización por la ocupación del nuevo sistema.

Palabras clave: Territorio; déficit habitacional; prácticas estatales; hábitat rural 


\title{
Deterritorialization in housing policies. The case of Law No. 6.758/05: Provincial Rural Housing Program in Santiago del Estero (Argentina)
}

\begin{abstract}
The state, within the framework of a development strategy in face of the risk and vulnerability implied by the housing deficit, promotes housing policies that influence the transformation of space and the configuration of the population's territorialities. However, state practices and representations on habitat problems respond to the degree of hegemony that it exerts, imposing itself on local habitat conditions and socio-cultural frameworks. In this sense, this work analyzes the logic of territorialization derived from the conceptualizations implied in Provincial Law No. 6.758/05, enacted for the production of rural housing in Santiago del Estero province. To achieve that goal, this work focused on four axes: the delimitation of the housing problem / solution, the guidelines regarding the policy execution process, the beneficiary and the housing solution. It was observed that the rural housing policy based on this Law would affect the space, implying a process of deterritorialization due to the modification of the characteristics of the previous dwelling system and another of reterritorialization due to the occupation of the new system.
\end{abstract}

Keywords: Territory, housing deficit, state practices, rural habitat

\section{Desterritorialização em políticas de moradia. 0 caso da lei № 6758/05: Programa Provincial de Moradia Rural de Santiago del Estero (Argentina)}

\section{Resumo}

O Estado, em um contexto de estratégia de desenvolvimento perante o risco e a vulnerabilidade que gera o déficit habitacional, promove políticas de moradia que incidem na transformação do espaço e na configuração das territorialidades da população. Porém, as práticas e representações sobre as problemáticas de hábitat respondem ao grau de hegemonia que exerce, impondo-se sobre as condições locais de hábitat e espaço sociocultural. Neste sentido, o trabalho analisa a lógica de territorialização derivada das conceptualizações da Lei Provincial №6758/05, declarada para a produção de moradias rurais na província de Santiago del Estero. Para isso, este trabalho pus o eixo em: a delimitação do problema/solução habitacional, as diretrizes a respeito do processo de execução da política, os destinatários e a solução habitacional. Observou-se que a política da moradia rural baseada nesta Lei, influi no espaço participando de um processo de desterritorialização pelas modificações das características do sistema de habitar prévio e outro de reterritorialização pela ocupação do novo sistema.

Palavras-chave: Território; déficit habitacional; práticas estaduais; hábitat rural 


\section{Introducción}

Desde las primeras acciones aisladas en la producción de vivienda a fines del siglo XIX destinadas al asentamiento rural de colonias de inmigrantes (Flores, 2006) hasta la política pública de vivienda estructurada en 1972 a través el Fondo Nacional de la Vivienda (FONAVI) como instrumento de acción (Cuenin y Moya, 2010), ningún programa destinado a vivienda rural estuvo sistemáticamente organizado en la agenda política argentina. Recién con los cambios estructurales ocurridos en la década de 1990 con la descentralización en la producción de vivienda mediante la Ley Nacional 24.464/95 en favor de las provincias (Lentini, 2005) se avizoró un cambio en tal sentido mediante la creación de los Institutos Provinciales de Vivienda (IPVs). A ellos se transfirió, entre otras injerencias, la tarea de diversificar las modalidades de las operatorias por fuera de la producción convencional del FONAVI. Las nuevas operatorias se formularon partiendo de las características de los estratos sociales y la focalización de las soluciones habitacionales en grupos y necesidades particulares; esta coyuntura política propició el surgimiento de programas de vivienda específicamente destinados a áreas rurales (Barreto, 2012).

El inicio del nuevo milenio encontró a la Argentina inmersa en un contexto de importante crisis estructural; para superarla, se impulsaron cambios en las políticas de desarrollo con mayor intervención del estado. En efecto, se realizaron mayores inversiones destinadas a las obras de infraestructuras, de equipamientos sociales y vivienda, esta última enmarcada en lo que se denominó Política Federal de Vivienda (PFV) (Barreto, 2012). La PFV se llevó a cabo mediante la intervención por programas, direccionando su atención a los sectores más afectados por problemas de pobreza y con necesidades habitacionales apremiantes como las comunidades aborígenes y los ámbitos rurales.

En este contexto de crisis nacional, la provincia de Santiago del Estero sumaba una serie de situaciones devenidas de un proceso histórico de violaciones de los derechos humanos, crímenes de lesa humanidad, malversación de fondos públicos y manipulación de estadísticas oficiales que devastaron la provincia. Alcanzada una situación límite, el Estado nacional impulsó la intervención federal de la provincia, y desarticuló el régimen político que sostuvo la hegemonía en el poder por décadas. Respecto a las políticas de vivienda, el régimen previo a la intervención federal acumulaba una sucesión de denuncias de múltiples casos de corrupción organizado bajo un modelo de gestión cuya estructura era fuertemente clientelar (Dargoltz et al., 2006). El nuevo gobierno implementó asignaciones de vivienda mediante sorteo público y, al mismo tiempo, anunció un explosivo aumento de la inversión que permitiría quintuplicar la construcción 
de viviendas e infraestructuras asociadas. De este modo, la producción de vivienda se convirtió en un punto neurálgico de la política provincial.

Cabe señalar que, Santiago del Estero ha presentado el mayor índice de población rural del país conjugado con graves problemas sociales y productivos. Este panorama obligó a la PFV a iniciar acciones para atender la falta de una estructura institucional y política que pudiera aplicar políticas de vivienda en el espacio rural. Hasta ese momento, la construcción de viviendas se había concentrado en los centros urbanos en detrimento de las localidades de menor población. Según Legname (2012), dicha política supuso un proceso de desterritorialización particular de la población campesina en la medida que favoreció la migración interna a las ciudades como una consecuencia de las numerosas necesidades básicas insatisfechas, entre ellas, el déficit habitacional. En efecto, el IPVU elaboró las bases mediante el cual se materializó la Ley Provincial № 6.758 (2005), en la que se estipuló la creación de un Programa Provincial de Vivienda Rural, junto a un conjunto de disposiciones orientadas a la ejecución del mismo (Legname, 2012). No obstante, su formulación e implementación, ligada a dinámicas de ordenamiento y control territorial, se condenso en prácticas y representaciones espaciales para promover una nueva territorialidad frente a las relaciones y dinámicas que han estructurado los modos de vida campesino hasta el momento (Mocase y ESfÀ, 2005). Asimismo, dicha lógica se presentaba mediante un discurso referido a la "erradicación de ranchos" que aún perdura estigmatizando el hábitat y la territorialidad del espacio rural (Mandrini, Cejas y Bazán, 2018).

Por lo mencionado, cabe preguntarse si estas prácticas y representaciones estatales partieron de conceptualizaciones que permitiesen resolver 0 , por el contrario, agudizar la problemática del hábitat rural santiagueño, en la medida en que se alteren y/o modifiquen las formas históricas de habitar sus territorios rurales. Es decir, resignando las condiciones existenciales previas a la adquisición de la vivienda por nuevas condiciones concebidas e impuestas desde las esferas estatales.

A raíz de dicho cuestionamiento, el artículo propone analizar la lógica de territorialización derivada de las conceptualizaciones volcadas en la Ley provincial $N^{\circ} 6.758 / 2005$, y sus posibles efectos sobre el espacio rural de Santiago del Estero.

La estrategia metodológica de este trabajo se basa en la segregación de los conceptos plasmados en la Ley Provincial № 6.758/2005 y el análisis puntual de cada uno de ellos frente a las características contextuales del territorio rural en el que se insertan. En tal sentido, se hizo hincapié en las lógicas de territorialización implicadas en tales conceptos, según las concepciones y representaciones expuestas sobre el espacio y la población rural de la provincia. Por lo tanto, el argumento del texto se sustenta en 
la sistematización de información proveniente de boletines oficiales, marcos normativos, bibliografía especializada y bases de datos de organismos públicos.

\section{Espacio, territorio y territorialización}

El espacio resulta de una apropiación y dominación planificada de la naturaleza que hace imposible disociar lo natural de lo social, no es independiente de las relaciones sociales que se desarrollan en él y éstas determinan al objeto/sujeto que se constituye a través de y con el espacio (Haesbaert, 2012). Giménez (1999) plantea dos formas de apropiación del espacio: una de carácter instrumental-funcional en el que se enfatiza la relación utilitaria con el espacio; y otra de carácter simbólico-expresivo como espacio de sedimentación socio-cultural y soporte de identidades colectivas. Las relaciones sociales están atravesadas por relaciones de poder a través de las cuales establecen un orden y control específico en el espacio (Haesbaert, 2012) El ejercicio regular de este control espacial se constituye en prácticas y representaciones espaciales propias de cada grupo social que permiten controlar espacial y materialmente el acceso de algún flujo en el espacio (personas, mercancías, capitales, etc.), configurándose en un territorio (Sack, 1986). Haesbaert (2012) reconoce distintos territorios dependiendo del tipo de poder que se ejerza sobre él: los macroterritorios en relación a las grandes estructuras productivas, económicas y legales de los poderes soberanos en tanto poder de un estado o poder de los grupos hegemónicos, y los micro-territorios manifestados a partir de los movimientos de resistencias que son parte de las relaciones sociales y son configuradoras de un territorio singular. De este modo, el espacio es un escenario de disputas simultáneas entre los intereses de reproducción del capital que se manifiestan en macro-territorios y la viabilidad y resolución de las condiciones de vida materiales y sociales de quienes habitan en los micro-territorios.

El poder de accionar sobre el territorio conforma la territorialidad y su ejercicio activo la territorialización (Sack, 1986). Dado que las condiciones de existencia están inevitablemente en constante transformación, las situaciones de construcción y reconstrucción de los territorios es permanente y, con ello, el despliegue de procesos de territorialización, desterritorialización y reterritorialización; proceso negativo para las personas cuando la desterritorialización, provocada por la movilidad, precariza las condiciones materiales de vida y conlleva la pérdida de control del territorio, sobre todo para los grupos subalternos; y de igual modo actúa por inmovilidad cuando los límites territoriales son impuestos y quedan bajo control de actores externos (Haesbaert, 2012). 
La casa-habitación es la escala más elemental de producción del territorio, donde el espacio apropiado resulta en la intimidad e inmediatez en tanto prolongación territorial de nuestro cuerpo. La casa-habitación incorpora una dimensión de orden simbólico que la vincula directamente con la construcción de una identidad en el control, producción, adaptación, desplazamientos y usos del espacio, a partir de la cual las personas proyectan su manera de ser en el mundo (Giménez, 2005). En tal sentido, la vivienda rural es un organismo eminentemente activo e interactivo con el medio natural, el entorno construido y el ámbito comunitario, y en su conjunto aporta a las redes del tejido social de las comunidades campesinas (Sánchez Quintanar y Jiménes Rosas, 2015). Cuando el Estado interviene por medio de políticas habitacionales actúa directamente sobre estas redes, y tendrá la capacidad y escala territorial de transformar las lógicas y prácticas de territorialización que se construyen desde la casa-habitación.

\section{Las lógicas de territorialización implícitas en la Ley Provincial Nº6.758/05}

Las políticas de vivienda forman parte del ordenamiento territorial de un estado y se enmarca en una estrategia de desarrollo frente al riesgo y vulnerabilidad que implica el déficit habitacional. Sin embargo, la orientación de tales políticas persigue un modelo habitacional afín a un sistema de prácticas y representaciones mediante el cual se identifica el problema y se gestan los procedimientos de intervención de los programas de vivienda. Asimismo, dicho sistema se compone de enunciados que les confieren estructura a los hechos y crean un orden de significados cuando el estado interviene produciendo material y funcionalmente un territorio (Haesbaert, 2012).

Por consiguiente, la intervención de una política habitacional expresa una lógica de territorialización determinada por las formas de concebir el problema/solución habitacional, las directivas del modelo de implementación y ejecución, la definición de los grupos sociales destinatarios y las consideraciones arquitectónicas de la solución habitacional. Tales aspectos, considerados en la segregación de los conceptos plasmados en la Ley Provincial $N^{\circ} 6.758 / 05$ configuran un conjunto de variables y observables que se desprenden de la relación entre la naturaleza del enunciado y las representaciones sobre el territorio (Cuadro $\mathrm{N}^{0} 1$ ).

\section{La delimitación del problema/solución habitacional}

Un aspecto central en la declaración de la Ley Provincial No 6.758 (2005) es la focalización en el espacio rural, ámbitos del territorio nacional postergados en las políticas públicas de vivienda (cuadro № 1 ). En 
Cuadro $N^{\circ}$ 1: Desagregación de los conceptos plasmados de la Ley Provincial № 6.758/05

\begin{tabular}{|c|c|c|c|c|}
\hline $\begin{array}{l}\text { Aspecto } \\
\text { desagregado }\end{array}$ & Variable & $\begin{array}{l}\text { Unidad de } \\
\text { observación }\end{array}$ & Conceptos de la Ley $N^{\circ} 6.758$ & Art. \\
\hline \multirow{4}{*}{$\begin{array}{l}\text { La delimitación del } \\
\text { problema/solución } \\
\text { habitacional }\end{array}$} & \multirow{2}{*}{$\begin{array}{l}\text { Identificación y } \\
\text { delimitación de la } \\
\text { política habitacional }\end{array}$} & $\begin{array}{l}\text { Politica de } \\
\text { vivienda rural }\end{array}$ & $\begin{array}{l}\text { Destinatario: habitantes de zonas rurales no incluidos } \\
\text { en programas oficiales de vivienda }\end{array}$ & 1 \\
\hline & & $\begin{array}{l}\text { Delimitación de la } \\
\text { problemática }\end{array}$ & Alcance: localidades de menos de 2000 habitantes & 2 \\
\hline & \multirow[t]{2}{*}{$\begin{array}{l}\text { Relación } \\
\text { problema/solución }\end{array}$} & \multirow[t]{2}{*}{$\begin{array}{l}\text { Propósitos de la ley } \\
\text { provincial }\end{array}$} & $\begin{array}{l}\text { Problemas: calidad de vida deficitaria; expulsión de } \\
\text { población rural; débil desarrollo de actividades productivas, } \\
\text { potencialidades humanas y recursos existentes; escaso } \\
\text { desarrollo y estructuración territorial; crecimiento } \\
\text { desequilibrado }\end{array}$ & 2 \\
\hline & & & $\begin{array}{l}\text { Fomento: estadios de desarrollo armónico y equilibrado; } \\
\text { promoción social, arraigo }\end{array}$ & 3 \\
\hline \multirow{9}{*}{$\begin{array}{l}\text { Las directivas } \\
\text { del proceso de } \\
\text { ejecución de la } \\
\text { politica }\end{array}$} & \multirow[t]{2}{*}{$\begin{array}{l}\text { Función de la } \\
\text { institución autorizada }\end{array}$} & Rol del IPVU & $\begin{array}{l}\text { Competencias: autoridad de aplicación, elaboración de } \\
\text { planes y programas }\end{array}$ & 4 \\
\hline & & $\begin{array}{l}\text { Condiciones del } \\
\text { proyecto de vivienda }\end{array}$ & $\begin{array}{l}\text { Adecuación y aprovechamiento local: a las condiciones del } \\
\text { ambiente, actividades y costumbres de cada región; } \\
\text { materiales de producción u obtención local. }\end{array}$ & 4 \\
\hline & \multirow[t]{3}{*}{ Financiamiento } & \multirow[t]{2}{*}{$\begin{array}{l}\text { Sistema de } \\
\text { financiamiento }\end{array}$} & $\begin{array}{l}\text { Beneficio: crédito a largo plazo y bajo interés; subvención, } \\
\text { ante imposiblidd de contraer compromiso de pago }\end{array}$ & 4 \\
\hline & & & Financiamiento: fondos para Programa de Vivienda Rural & 7 \\
\hline & & $\begin{array}{l}\text { Electrificación y } \\
\text { dotación de agua } \\
\text { potable }\end{array}$ & $\begin{array}{l}\text { Infraestructura: gestión para electrificación rural y dotación } \\
\text { de agua potable }\end{array}$ & 8 \\
\hline & \multirow{4}{*}{$\begin{array}{l}\text { Propiedad del } \\
\text { inmueble }\end{array}$} & \multirow[t]{3}{*}{ Situación dominial } & Estado dominial: Regularizar la situación dominial & 3 \\
\hline & & & $\begin{array}{l}\text { Instrumento: utilidad pública y sujeto a expropiación a } \\
\text { todos los bienes inmuebles que sean necesarios, según } \\
\text { Ley } N^{\circ} 4.630 \text {. }\end{array}$ & 9 \\
\hline & & & $\begin{array}{l}\text { Origen de los fondos: el importe de expropiación se } \\
\text { acumularán al valor final de la vivienda }\end{array}$ & 9 \\
\hline & & Superficie a expropiar & $\begin{array}{l}\text { Criterio: Superficie máxima de terreno a expropiar de dos } \\
\text { mil quinientos metros cuadrados }\left(2.500 \mathrm{~m}^{2}\right)\end{array}$ & 9 \\
\hline \multirow[t]{3}{*}{ Los destinatarios } & \multirow[t]{2}{*}{$\begin{array}{l}\text { Especificación de } \\
\text { los destinatarios }\end{array}$} & $\begin{array}{l}\text { Grupos sociales } \\
\text { destinatarios }\end{array}$ & $\begin{array}{l}\text { Grupo social: mayores de edad, menores emancipados, } \\
\text { grupo familiar estable de por lo menos tres personas. }\end{array}$ & 5 \\
\hline & & $\begin{array}{l}\text { Acreditación de los } \\
\text { destinatarios }\end{array}$ & $\begin{array}{l}\text { Requisitos: sin deudas por créditos para vivienda; vivienda } \\
\text { deficitarias; demostrar residencia en el lugar de por lo } \\
\text { menos } 5 \text { años }\end{array}$ & 5 \\
\hline & $\begin{array}{l}\text { Responsabilidad de } \\
\text { los destinatarios }\end{array}$ & $\begin{array}{l}\text { Cancelación del } \\
\text { crédito }\end{array}$ & $\begin{array}{l}\text { Condiciones de adjudicación: el adjudicatario no podrá, } \\
\text { sin cancelación del crédito, enajenar, arrendar, dar en } \\
\text { aparcería o disponer de los inmuebles }\end{array}$ & 5 \\
\hline \multirow{5}{*}{$\begin{array}{l}\text { La solución } \\
\text { habitacional }\end{array}$} & \multirow[t]{3}{*}{ Marco tecnológico } & \multirow{3}{*}{$\begin{array}{l}\text { Tecnologias de la } \\
\text { solución habitacional }\end{array}$} & Tipo: Vivienda digna & 1 \\
\hline & & & $\begin{array}{l}\text { Adecuación y aprovechamiento local: a las condiciones del } \\
\text { ambiente, actividades y costumbres de cada región; } \\
\text { materiales de producción u obtención local. }\end{array}$ & 4 \\
\hline & & & $\begin{array}{l}\text { Resultados esperados: desarrollo de las potencialidades } \\
\text { humanas y aprovechamiento de los recursos existentes }\end{array}$ & 2 \\
\hline & \multirow[t]{2}{*}{$\begin{array}{l}\text { Tecnologia de } \\
\text { la vivienda }\end{array}$} & $\begin{array}{l}\text { Diseño de la solución } \\
\text { habitacional }\end{array}$ & $\begin{array}{l}\text { Criterios de diseño: atención a necesidades habitacionales } \\
\text { y a los usos y costumbres; estado edilicio de la vivienda } \\
\text { original; diseños acordes a la idiosincrasia y modos de vida }\end{array}$ & 3 \\
\hline & & $\begin{array}{l}\text { Infraestructuras de } \\
\text { servicios y producción }\end{array}$ & $\begin{array}{l}\text { Objetivo: desarrollo de los asentamientos } \\
\text { humano en función de sus actividades productivas }\end{array}$ & 2 \\
\hline
\end{tabular}

Tipo y calidad: condiciones de habitabilidad, infraestructuras 3 básicas, sistemas tradicionales, tecnologías no convencionales

Fuente: Elaboración propia. 
efecto, el artículo $1^{\circ}$ de la ley declara la creación del Programa Provincial de Vivienda Rurales y postula: "estará orientado a la inclusión de los habitantes de zonas rurales en planes de vivienda oficiales" (Ley Provincial ${ }^{\circ}$ $6758,2005)$. Ahora bien, previamente la provincia implementó políticas de vivienda rural, por lo cual, es preciso considerar las lógicas de territorialización implicadas en tales experiencias.

Una de las políticas fue implementada en 1979, cuando se sancionó la Ley № 4.808/79 que creaba el Programa de Viviendas Económicas Rurales, destinada a la atención de la problemática del mal de Chagas y a desalentar procesos migratorios del área rural hacia los centros urbanos (Passeri, 2001). Dicho programa diagnosticaba que no era posible abordar el desarrollo urbano, sin intervenir simultáneamente en las poblaciones rurales dispersas que sufrían el mayor impacto del déficit habitacional. Sin embargo, las dificultades de localización de las poblaciones dispersas no fueron posibles de soslayar, anulando la intervención en estas áreas y el programa concentró la construcción de viviendas en áreas urbanas y rurales agrupadas. A su vez, el programa exponía oficialmente un discurso higienista destinado a sustituir la vivienda precaria representada en la vivienda rancho, fomentando de esta manera una materialidad ligada a lo urbano y estigmatizando las tradicionales del medio rural (Mandrini et al., 2018).

En los 90, el Programa de Solidaridad Santiagueña y Programa de Viviendas Populares modificaron su enfoque en términos administrativos, pero continúo con las líneas de acción de los programas previos respecto a la localización y concentración de la política habitacional, postergando a las poblaciones rurales aisladas (Passeri, 2001).

En efecto, las políticas previas a la Ley iniciaron un proceso de organización del sistema de gobierno, que ante las dificultades para resolver de forma eficiente las condiciones habitacionales de la población rural aislada, orientó sus acciones a agruparlas y por ello a relocalizarlas y urbanizarlas. Ello evidencia que, el estado ante sus propias limitaciones para observar y resolver la problemática del hábitat rural recurre a los mecanismos empleados anteriormente y actúa imponiendo una forma de ocupación territorial distinta a los modos de habitar el espacio rural. Es decir, induce un proceso de desterritorialización por la falta de correlación con la ocupación del espacio de la población rural y desplazando a las mismas, alterando su territorialidad ligada a su lugar de origen, prácticas y costumbres. En tal sentido la continuidad de ciertas prácticas de gobierno suministra un marco de legitimidad al conjunto de acciones u omisiones que desempeña. Desde esta perspectiva, las prácticas estatales de las políticas de viviendas pueden actuar confiriendo autoridad a ciertos patrones de poder y de este modo, instituir sus representaciones respecto a las formas de habitar. 
En cuanto a la delimitación de la población destinataria del programa de viviendas, la ley expresa en el artículo $2^{\circ}$ que serán: "en particular, localidades de menos de dos mil (2.000) habitantes" (Ley Provincial $N^{\circ}$ $6758,2005)$. Dicha delimitación se desprende del enfoque que utiliza el Instituto Nacional de Estadísticas y Censos de Argentina (INDEC), en el cual se caracteriza socio-demográficamente a la población rural agrupada como aquellas que residen en localidades de menos de 2.000 habitantes y a la rural dispersa como aquella que vive en campo abierto sin constituir centros poblados. Ahora bien, la vigencia de dicho enfoque ha despertado una serie de discusiones respecto a la insuficiencia con la cual opera en la caracterización de la heterogeneidad y diversidad de la población rural. Ello se debe a que la diferenciación del espacio no es neutral, en tanto responde a una visión dicotómica entre lo urbano y lo rural como ámbitos contrapuestos, donde lo rural asume una característica residual generalmente asociada a condiciones de pobreza, atraso, aislamiento y producción principalmente primaria (Castro y Reboratti, 2008).

Según los datos de los últimos dos censos nacionales, la población rural de la provincia presentó un incremento de un 30,97\% en 2001 a un $31,1 \%$ en 2010 , en contrapartida a la situación a nivel nacional donde la población rural total experimenta una reducción del $6 \%$ para el mismo periodo interesal (INDEC, 2001, 2010). Datos a destacar, porque indican que la provincia es una de las menos urbanizadas del país y en donde la población rural constituye un componente significativo de la misma. Por otro lado, a juzgar por la distribución socio-espacial de la provincia, son pocas las localidades de más de 2.000 habitantes (fig. $\mathrm{N}^{\circ} 1$, a) y poblaciones rurales agrupadas (fig. № 1, b), por el contrario, la población rural dispersa ocupa la totalidad de la misma (fig. № 1 , c). En efecto, tal distribución implica que el rango de intervención del programa de vivienda abarca aproximadamente la totalidad de la provincia.

Si bien la Ley no expone de forma directa las problemáticas ligadas a su origen, las mismas pueden evidenciarse a partir de la relación problema/solución incorporada en la conceptualización de sus objetivos, tales como:

Coadyuvar a la promoción social y desarrollo. (art.1); mejorar la calidad de vida. (...) desalentar procesos migratorios (...) desarrollo de las potencialidades humanas y recursos existentes. (art.2); arraigo de la población en su lugar de origen. (art. 3) (Ley Provincial No 6758, 2005).

De acuerdo a lo redactado por la ley; el estado provincial reconoce la necesidad de mejorar las condiciones de vida para incidir en los procesos sociales ligados al nivel de vulnerabilidad social que expulsa a los habitan- 
tes de sus territorios. Asimismo, plantea aprovechar las potencialidades sociales y materiales inherentes a la territorialidad del habitante rural. Sin embargo, si vinculamos los conceptos de vulnerabilidad y potencialidades a los de desarrollo, promoción social y calidad de vida, éstos se construyen a partir de datos representados en indicadores estructurados en los parámetros de la vida urbana y, por lo tanto, son condensados en variables que no son representativas de las formas de vida del ámbito rural. En cuanto a la vivienda, la misma forma parte de los instrumentos de diagnóstico para determinar el umbral de las condiciones de vida y de este modo, el estado establece el rango de una vivienda adecuada (Lazzari, 2012). En efecto, el predominio de la tipología de vivienda rancho en las áreas rurales dispersas (fig. $\mathrm{N}^{\circ} 2, \mathrm{c}$ ), conlleva a concentrar el déficit habitacional de la provincia en este sector (Passeri, 2008). En tal sentido, el hábitat rural resulta en un indicador contrapuesto a la vivienda adecuada considerada en tales instrumentos, invalidando con ello las potencialidades que plantea la ley.

Figura $N^{\circ} 1$. Distribución de la vivienda rancho.

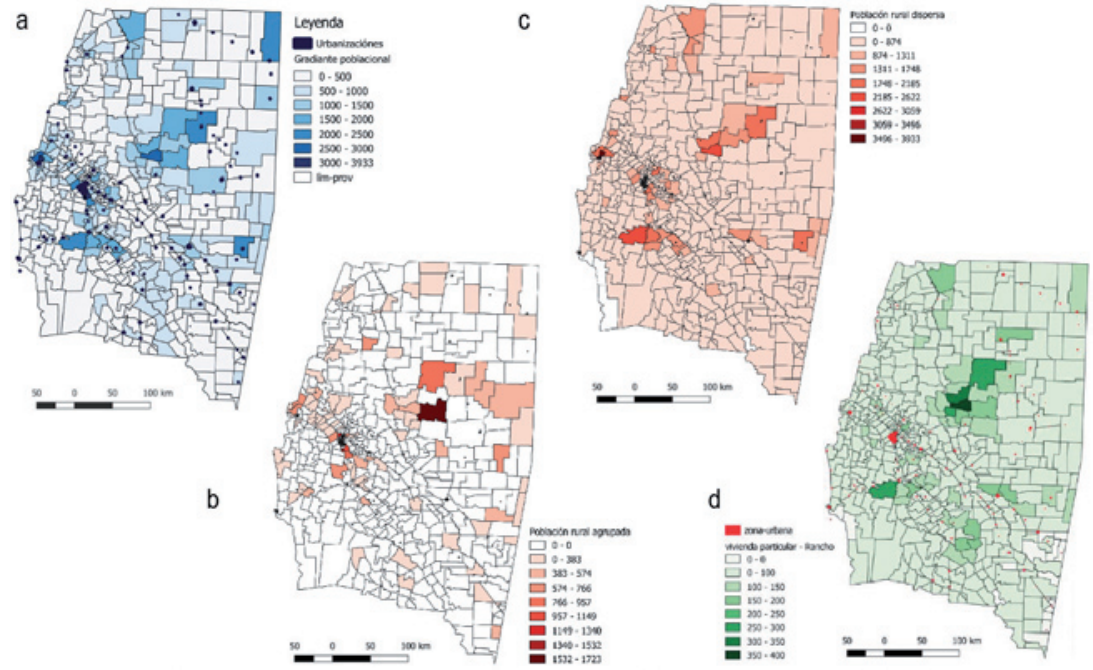

Referencias: a. Población total, b. Población rural agrupada, c. Población rural dispersa, d. Distribución de viviendas rancho Fuente: Elaboración propia en base a los datos por radio censal de la provincia de Santiago del Estero del Censo Nacional de Población, Hogares y Vivienda del 2010 (INDEC, 2010)

Por otra parte, entre los propósitos de la Ley es posible identificar algunas problemáticas vinculadas a la planificación territorial, cuando enuncia:

iniciar el camino hacia la estructuración territorial sobre la base de un desarrollo y crecimiento económico equilibrado (...) en función de sus actividades productivas. (art. 2), previsión de futuros estadios de desarrollo de 
los emplazamientos, que permitan un crecimiento armónico y organizado de las comunidades. (art. 3) (Ley Provincial № 6.758, 2005).

Tales propósitos dan cuenta de una estructura territorial irresuelta en términos de desarrollo económico, por lo cual cabe preguntarnos: ¿Qué tipo de desarrollo alternativo plantea y para qué habitante rural? En tal sentido, es preciso señalar que la provincia se conforma de una estructura agraria inequitativa respecto al espacio, caracterizada por la concentración de la propiedad de la tierra por parte de grupos empresarios (Paz et al., 2015). Esta estructura es el resultado de políticas basadas en un modelo de desarrollo que impulsó la expansión de las fronteras agropecuarias, en una provincia que exhibe un porcentaje elevado de tenencia precaria de la tierra sin título legal, implicando el desplazamiento forzoso de las poblaciones rurales (Barbetta, 2009).

Ahora bien, según los datos del Censo Nacional Agropecuario, Santiago del Estero presentaba del total Explotaciones Agropecuarias (EAPs) cerca de un $70 \%$ EAPs de pequeños productores familiares (INDEC, 2002). Estas últimas, en la medida que confrontan con el régimen de propiedad del modelo agroindustrial, desarrollan estrategias que le permiten resistir a un contexto de hostilidades geográficas, económicas y sociales, ligadas a los recursos que provee el ambiente. Sin embargo, pese a la importancia cuantitativa que este sector representa, aún no han sido captados en su dinámica y potencialidad productiva en materia de políticas públicas (Paz et al, 2014). Por el contrario, la intromisión del modelo de desarrollo agroindustrial suscita múltiples instancias de conflictos en torno a la ocupación asimétrica del territorio. Situación que ha provocado el surgimiento de numerosas organizaciones sociales que reivindican sus territorialidades en torno a sus prácticas culturales, con la consigna de "la lucha por la tierra" (Olivarez y Fonzo Bolañez, 2021). Ello evidencia las exigencias de un modelo de desarrollo con otro sentido sobre el espacio y otra dimensión política del territorio, ligado a narrativas e imaginarios antagónicos a la idea de bienestar plasmada en la noción de crecimiento económico que plantea el estado. Por lo tanto, las estrategias estatales de desarrollo rural resultan en una fuerza de transformación profunda de la realidad económica, social y política de las sociedades rurales, en tanto tiende a invisibilizar la multiplicidad de riquezas del territorio e inhabilitar con ello, los conocimientos empíricos locales en la planificación de políticas públicas.

\section{Las directivas en la ejecución de la política}

En las políticas habitacionales argentinas subsiste una combinación entre la institucionalidad federal y aquellas vinculadas a los diferentes 
programas provinciales. Por consiguiente, de acuerdo a los lineamientos establecidos desde la nación, las competencias provinciales involucran el diseño, financiamiento, administración e implementación. En tal sentido, las consideraciones de la ley al respecto, son incorporadas en el artículo $4^{\circ}$ cuando redacta: "El Instituto Provincial de Vivienda y Urbanismo será la autoridad de aplicación de la presente Ley, y elaborará los planes de fomento del Programa de Vivienda Rural" (Ley Provincial No $6758,2005)$.

Ahora bien, en la estructura administrativa de las políticas nacionales de vivienda, quien dictaminan los principales lineamientos es el Poder Ejecutivo Nacional, modelando un sistema de gestión a través del Ministerios de Planificación Federal, Inversión Pública y Servicios (MPFIPyS). La Subsecretaría de Desarrollo Urbano y Vivienda del MPFIPyS financia y toma las decisiones en planificación, ejecución y control de toda la obra pública nacional y es responsable del sistema de transferencia de fondos a las diferentes jurisdicciones provinciales. En efecto, es potestad de esta secretaría reglamentar los diseños de las soluciones habitacionales a las cuales deben atenerse los IPVs y, por lo tanto, éstos encuentran limitaciones para la formulación de alternativas adecuadas a los contextos locales, ateniéndose al rol de ejecutores de las políticas de vivienda. En tal sentido, las restricciones impuestas a los IPVs invalidan el principio de federalización de las políticas de vivienda.

Pese a las limitaciones mencionadas, la Ley plantea algunas consideraciones vinculadas al diseño de la vivienda a tener en cuenta por el IPVU, cuando redacta:

los proyectos y planes que elabore para la construcción, deberán sujetarse a las condiciones de clima, ambiente, actividades y costumbres de cada región, tratando de aprovechar en la construcción los materiales que se produzcan o sean factibles de obtener en la zona. (art. 4) (Ley Provincial № 6758,2005$)$.

Dichas consideraciones manifiestan que la ley aspira a la adecuación del programa de vivienda a las formas de ocupación y tecnologías locales. Sin embargo, no es posible ajustar el proyecto de vivienda en tal sentido, dado que las materialidades basadas en los recursos existentes del hábitat rural de la provincia no están consideradas en las reglamentaciones técnicas nacionales o están prohibidas.

Una de las obligaciones de los IPVs es la administración de los recursos financieros para el funcionamiento de los programas de vivienda y el recupero de las deudas por las viviendas ya entregadas. Respecto a ello se declara en la Ley: 
Créase el "Fondo para Programa de Vivienda Rural" (art. 7); la financiación de los montos necesarios para las obras se concederá a largo plazo y bajo interés (...) de acuerdo a las actividades que desarrolle el beneficiario (...) subvencionar a aquellos moradores que, por razones económicas, debidamente fundadas, no pudiesen contraer tal compromiso de pago. (art. 4); financiar los aportes de los usuarios de la electrificación rural (...) hacer préstamos a través del sistema de créditos asociativo a grupos de vecinos para la dotación de agua potable. (art. 8) (Ley Provincial № 6758, 2005).

Por lo enunciado, la Ley expone dos alternativas respecto a la forma de asignación de la vivienda: por recupero y por subvención. Sin embargo, del total de EAPs, el 72\% representa a los pequeños productores de menor nivel de capitalización (CNA, 2002). En tal sentido, las dificultades para la capitalización del trabajo y acceso al consumo son grandes, apenas resarcidas por la intensificación de la mano de obra familiar y comunitaria y el aprovechamiento de los recursos naturales presentes (Paz et al., 2015). En efecto, dicho sector subsiste en un marco donde pondera el capital social y ecológico por sobre el capital financiero planteado en la ley y por ello solo admite la forma de asignación por subvención.

Respecto al acceso a infraestructuras de servicios en el espacio rural, es preciso destacar que para 2001 , del total de la población rural dispersa de la provincia, el 75,05\% carecía de acceso a la red eléctrica y el $76,20 \%$ de acceso a red de agua corriente (INDEC, 2001). Esto responde a que dicha población habitualmente se ubica al interior de áreas boscosas y apartadas de las redes e infraestructura de servicios y viales. Lo cual expresa la relevancia de este aspecto de la ley, sin embargo, se presentan dos problemas: por un lado, se propone un método financiero que no se condice con las capacidades económicas del habitante rural y por otro, se priorizó la construcción de viviendas sobre rutas nacionales y provinciales para garantizar el acceso a servicios básicos y el suministro de materiales convencionales de construcción (Legname, 2012.)

Otro eje de discusión que plantea la norma consiste en la seguridad jurídica de la propiedad de la tierra. De hecho, la regularización del dominio se contempla en la Ley cuando redacta:

regularizar la situación dominial de su emplazamiento en los casos que así lo requieran. (art. 3); Declárase de utilidad pública y sujetos a expropiación a todos los bienes inmuebles que sean necesarios para la ejecución del presente Programa Habitacional a favor de beneficiarios que no posean títulos dominiales de los terrenos (...) previo informe que sobre la posesión (...) La adjudicación bajo este procedimiento se perfeccionará mediante un contrato específico, facultándose al Instituto Provincial de Vivienda y Urbanismo a suscribir con los beneficiarios el acuerdo (...) el importe que surja de la 
expropiación se acumularán al valor final de la vivienda (...) estableciéndose como la superficie máxima del terreno a expropiar a dos mil quinientos (2.500) metros cuadrados. (art. 9) (Ley Provincial № 6758, 2005).

Cabe recordar que el modelo territorial que favoreció la expansión de las fronteras agropecuarias ha desencadenado una serie de conflictos entre empresarios y campesinos (Paz et al. 2015), por el enfrentamiento entre dicho modelo y el régimen de tenencia precaria de la tierra que afecta al $39,64 \%$ de la población rural dispersa (INDEC, 2001). En el marco jurídico general, el instrumento legal con el que cuenta la población rural para el acceso a la propiedad es el de la prescripción adquisitiva por actos posesorios o ley veinteñal. Dicho instrumento se basa en la pérdida de derechos de una parte por el uso o usucapión por parte de la otra (en evidencia de un interés social). En efecto, se desencadena una disputa por el predio entre los detentores de dominio (empresarios) que carecen de posesión del inmueble y su contraparte, campesinos que carecen de títulos, pero reúnen la condiciones para solicitar la prescripción adquisitiva (Barbetta, 2010). En la medida que la Ley $N^{\circ} 6.758$ plantea un mecanismo de expropiación de los predios donde construirá la vivienda, desestima la vía de la prescripción adquisitiva invalidando los actos posesorios del habitante rural y, por lo tanto, postergando el acceso al derecho a la tierra. A su vez, dicho mecanismo impone un procedimiento que consiste en sobrecargar el costo de expropiación al destinatario para la compra de su propio terreno.

Respecto al impacto del proceso de expropiación para la construcción de las viviendas, cabe señalar que esta acción afectaría potencialmente al $48,30 \%$ del total de EAPs, aquellas que son sin límites definidos, es decir en situación irregular de bienes (CNA, 2002). En efecto, el máximo de $2.500 \mathrm{~m}^{2}$ de superficie del predio a expropiar planteado por la ley resulta acotado y limitante si consideramos que el esquema de desarrollo local rural se sustenta en la articulación de la vivienda con amplios espacios para el pastoreo, cultivo y extracción forestal. Por lo cual, el predio no solo es mucho más amplio que lo que la ley contempla, sino que además su delimitación perpetúa la irregularidad en el resto del mismo, factor que incide en el temor de la población hacia posibles desalojos y pérdida del territorio.

\section{Los destinatarios}

En cuanto a los requisitos de los destinatarios la estipula:

Poseer como única, una vivienda en condiciones deficitarias (...) no poseer deudas por créditos para vivienda (...) Acreditar permanencia en el lugar 
de radicación de la vivienda de por lo menos cinco años (...) en caso de que el beneficiario no sea titular del dominio. (art. 5); El adjudicatario no podrá, bajo ningún aspecto hasta tanto no haya cancelado definitivamente el crédito, enajenar, arrendar, dar en aparcería o disponer bajo cualquier otra forma de contratación que implique la explotación directa o indirecta de la vivienda. (art. 6) (Ley Provincial № 6758, 2005).

De acuerdo a lo plasmado en la ley, es preciso subrayar que la persistencia de la población en su territorio se debe en gran parte a un usufructo de los recursos locales que resulta en un escaso nivel de capitalización, por lo cual la obligación de cancelar el crédito por la vivienda obliga al habitante rural a formar parte de una dinámica financiera que le es exógena y compleja de subsanar. Por otro lado, una condición para acceder al programa es poseer la vivienda rancho, a la cual el estado provincial concibe como vivienda deficitaria. Si bien, la ley no estipula la sustitución de la vivienda rancho, deja en claro que la misma es uno de los principales focos de la problemática habitacional. En efecto, la consideración del rancho como una antítesis del modelo de vivienda a construir se tradujo en la práctica en la obligación de desmantelarla al momento de la entrega de la vivienda nueva (Legname, 2012). De esta manera, la imposición de una tipología constructiva permite evidenciar un proceso de desterritorialización por eliminación de la vivienda anterior (y con ello todo el marco cultural y tecnológico vinculado) y de reterritorialización en la ocupación de una vivienda con características nuevas y exógenas.

\section{La solución habitacional}

En cuanto la solución habitacional, la Ley plantea su perspectiva arquitectónica para el diseño y materialidad de la solución habitacional, cuando declara:

posibilitando en forma rápida y eficiente la construcción, recuperación, rehabilitación, refacción y/o ampliación de viviendas dignas. (art.1) responder a las necesidades habitacionales del poblador rural acorde a sus usos y costumbres, su localización y al estado edilicio de su unidad habitacional (...) creación de las condiciones de habitabilidad proveyendo servicios de infraestructuras básicas, mediante sistemas tradicionales o tecnología no convencionales, en caso de que no exista disponibilidad infraestructural (...) haciendo prevalecer diseños arquitectónicos acordes a la idiosincrasia de sus moradores, modos de vida y hábitat. (art. 3); los proyectos y planes que elabore para la construcción deberán sujetarse a las condiciones de clima, ambiente, actividades y costumbres de cada región, tratando de aprovechar en la construcción los materiales que se produzcan o sean factibles de obtener en la zona. (art. 4) (Ley Provincial Nº 6758, 2005). 
Sí atendemos a las nociones plasmadas, es posible interpretar que el espíritu de la Ley proponía un cambio sustancial en términos de políticas de vivienda rural a como se venía desarrollando hasta el momento. El diseño arquitectónico plasmado en la Ley, concuerda con los patrones de hábitat insertos en un esquema de desarrollo endógeno y estratégico, que se caracteriza por la utilización de los recursos disponibles, humanos (mano de obra familiar) y naturales (tierra y vegetales), en la resolución constructiva de la vivienda rancho (MOCASE \& ESfÀ, 2005).

Cabe señalar que, solo la construcción que contiene a los dormitorios es lo que el estado interpreta como vivienda rancho (fig. $\mathrm{N}^{\circ} 2$, b) pero ésta suele estar acompañada de otras construcciones para el desarrollo de múltiples actividades, vinculando entre sí los ámbitos domésticos y los productivos. En efecto, la organización del peridomicilio de una unidad de vivienda reúne en torno a un patio una serie de edificaciones que responden a diversos requerimientos funcionales, como: dormitorios, cocina-comedor, almacén, pozo de agua, enramadas, letrina, fogón, hornos y otras intervenciones como los corrales para los animales, cultivos y represas para el almacenamiento del agua (fig. $N^{\circ} 2$, a) (MOCASE \& ESfÀ, 2005).

Los aspectos indicados arriba, en tanto están ligados a los modos de vida en el marco de una coyuntura histórica y geográfica determinada, forman parte del diseño arquitectónico que plantea la Ley para adecuarse las condiciones sociales, climáticas, económicas y ecológicas. No obstante, en simultáneo a creación de dicha Ley, el gobierno provincial tomó la decisión de priorizar la salud pública como política de estado para trabajar la concientización y erradicación de la Enfermedad de Chagas. Ello implicó una reevaluación de la problemática para responder a un alarmante aumento de casos agudos, cuyos pilares de acción contra la vinchuca (Triatoma infestans) eran: desinsectación, educación y mejoramiento de la vivienda (Llovet \& Dinardi, 2013). Lo cual indica que el gobierno provincial asoció directamente la proliferación de la vinchuca en el domicilio a las condiciones de habitabilidad en el medio rural y señala a la vivienda rancho como el principal foco de infección de la enfermedad. En efecto, la vivienda rancho fue interpretada como sinónimo de precariedad e insalubridad, asociado a una situación de atraso en términos de desarrollo social e índices emergentes de pobreza. Lo cual introduce e institucionaliza un discurso asociado a la erradicación de tales formas de resolver las necesidades del hábitat (Fig. № 2, d) en el desarrollo de las políticas públicas de vivienda rural, legitimando desde el estado una noción de poblador rural antagónico al formato de progreso y desarrollo hegemónico.

Frente a este panorama, el gobierno provincial adoptó la frase "Plan de erradicación de la vivienda rancho" para referirse al Plan Provincial de 
Vivienda Rural, (Legname, 2012). Por tales motivos, prosperó un prototipo realizado con tecnologías convencionales que difiere respecto de las formas y posibilidades de resolver el hábitat de las poblaciones rurales y en cierta medida anula los principales objetivos de adaptabilidad considerados por la Ley (fig. $\mathrm{N}^{\circ} 2, \mathrm{c}$ ). Esto evidencia que, sobre una conceptualización errónea de los factores de riesgo respecto de la enfermedad, centrado en la naturaleza del material y no de la calidad constructiva, se construyen argumentaciones que conllevan a la estigmatización del conocimiento técnico-cultural de las comunidades rurales.

Por lo mencionado, el desarrollo de las políticas habitacionales centradas solo en la reproducción de viviendas estandarizadas, se subordina ante una correlación de fuerzas sociales, políticas y económicas, en la cual se evidencia un esquema de negación de los procesos sociales, tecnológicos y políticos constituidos históricamente en las localidades en donde intervienen. Es decir, la intervención estatal resuelve el problema habitacional en función de sus propios instrumentos de diagnóstico sin consulta previa a los beneficiarios de las políticas, incidiendo en profundizar un proceso de desterritorialización por exclusión cultural y epistémica. Asimismo, despliega un proceso de reterritorialización para habitar la vivienda del programa, vinculado a nuevas prácticas en el uso del espacio y nuevos conocimientos sobre su materialidad.

Figura $\mathbf{N}^{\circ}$ 2. Organización y arquitectura del conjunto vivienda-rancho.
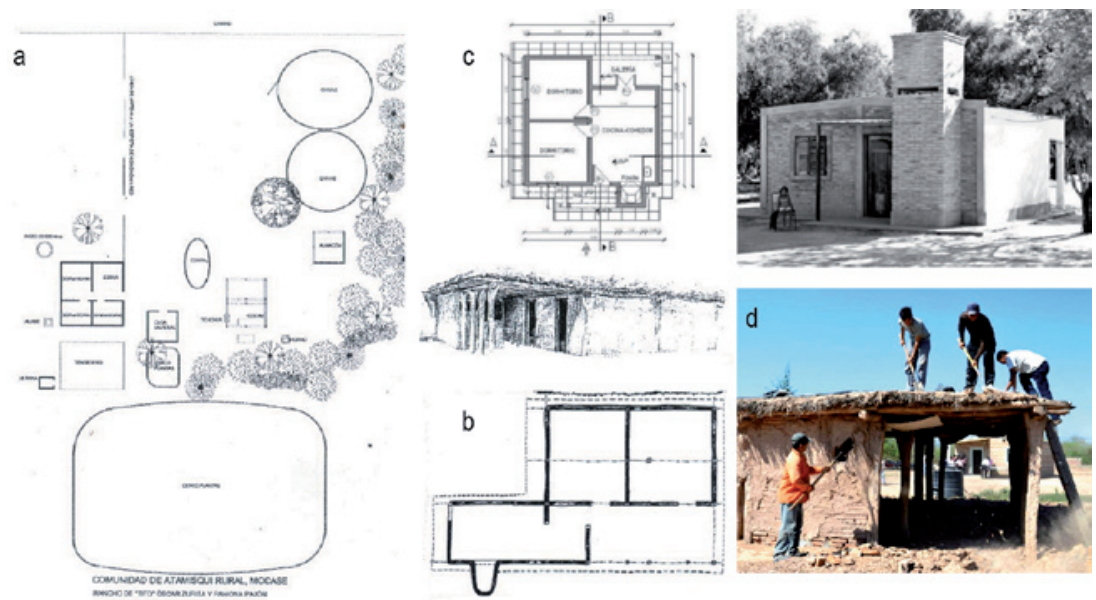

Referencias: a. Organización del peridomicilio de la vivienda rural, b. Planta y perspectiva de una vivienda rancho santiagueña, c. Planta y perspectiva de las primeras viviendas realizadas con el programa de vivienda rural, d. Destrucción de la vivienda rancho. Fuentes: a y b. MOCASE \& ESfÄ; 2005; c. Ministerio de Desarrollo Social Santiago del Estero, 2021; d. Foto: Germán Alcaide. 


\section{Conclusiones}

La Ley Provincial № 6.758/05 está inmersa en marcos legislativos y administrativos que la orientan hacia prácticas que transforman el espacio cuando ejecuta el programa de viviendas, provocando un proceso de desterritorialización. Las políticas de vivienda rural previas introdujeron lógicas de un modelo de desarrollo político y territorial urbano que se insertó bajo cierto grado de desconexión frente a las condiciones del hábitat rural de la provincia. En efecto, el afianzamiento de dichas lógicas se da con el Programa Provincial de Vivienda Rural, en las que el diagnóstico del problema, la planificación y ejecución no consideran la territorialidad del poblador rural expresadas en su hábitat, sus marcos culturales, económicos y tecnológicos. Por el contrario, privilegian las prácticas del estado respecto a un modelo de desarrollo territorial hegemónico y representaciones subjetivadas sobre la condición rural. Incluso cuando la ley reconoce las potencialidades inherentes a los modos de vida rurales, los procedimientos gestados en el interior de dichas prácticas estatales no admiten la incorporación de las mismas en el diseño de la política habitacional.

La ley en la medida que establece límites sobre superficie del predio y no considera la totalidad del mismo, perpetúa la negación del problema por invisibilización de la territorialización del habitante rural. Por lo tanto, aquellos beneficiarios de las políticas de vivienda estarían sujetos a un proceso de desterritorialización por la modificación de las características las particularidades de su sistema de habitar y otro de reterritorialización por la ocupación de un nuevo sistema. En tal sentido, en tanto el nuevo sistema es configurado por agentes externos vinculados a las lógicas de un modelo estatal mercantilista y urbano de producción de viviendas, establece un dominio que se impone progresivamente sobre el habitar de las personas y sus formas de territorialización.

\section{Referencias bibliográficas}

Barbetta, P. N. (2009). En los bordes de lo jurídico. Conflictos por la tenencia legal de la tierra en Santiago del Estero. UBA.

Barreto, M. A. (2012). Cambios y continuidades en la política de vivienda argentina (2003-2007). Cuadernos de Vivienda y Urbanismo, 5(9), 12-30.

Castro, H., \& Reboratti, C. (2008). Revisión del concepto de ruralidad en la Argentina y alternativas posibles para su redefinición. Serie Estudios e Investigaciones No 15.
Cuenin, F., \& Moya, R. (2010). Cambios en las políticas de vivienda social en la Argentina (1976-2007): ¿Cambiaron también los resultados habitacionales? BID, Sector de Capacidad Institucional y Finanzas, 33. Recuperado de http://idbdocs.iadb.org/wsdocs/ getdocument.aspx?docnum $=35458953$

Dargoltz, R., Gerez, O., \& Caeo, H. (2006). El Santiagueñazo: cambio político y régimen caudillista. (Biblos, Ed.), Historia Política Argentina (Vol. 1). Buenos Aires. 
Flores, F. C. (2006). Inmigración ruso-alemana y ruralidad. La colonia agrícola como forma de asentamiento. Temas de historia argentina y americana $N^{\circ}$, 107-124.

Giménez, G. (2001). Cultura, territorio y migraciones. Aproximaciones teóricas. Alteridades, 11(22), 5-14. Disponible en: https:// www.redalyc.org/pdf/747/74702202.pdf

Haesbaert, R. (2012). Del mito de la desterritorialización a la multiterritorialidad. Cultura y representaciones sociales, 9-42.

INDEC. Instituto Nacional de Estadística y Censos. (2001). Censo Nacional de Población, Hogares y Viviendas 2001. Procesado con Redatam $+S P$.

INDEC. Instituto Nacional de Estadística y Censos. (2002). Censo Nacional Agropecuario 2002.

INDEC. Instituto Nacional de Estadística y Censos. (2010). Censo Nacional de Población, Hogares y Viviendas 2010. Procesado con Redatam $+S P$.

Lazzari, R. (2012). El déficit habitacional en la Argentina: estimación para el año 2009. Cámara Argentina de la Construcción. Buenos Aires.

Legname, P. (2012). Política habitacional en la provincia de Santiago del Estero: hacia la revalorización del habitante rural, su identidad cultural y su entorno. Programa Provincial de Vivienda Rural. En $9^{\circ}$ Bienal del Coloquio de Transformaciones Territoriales (pp. 1-20). San Miguel de Tucumán.

Lentini, M. (2005). Política habitacional de Argentina y Chile durante los noventa. Un estudio de política comparada. Revista INVI, 20(55), 139-153.

Ley Provincial № 6.758. Programa Provincial de Vivienda Rural, (2005). Argentina.

Llovet, I., y Dinardi, G. (2013). Innovación, política pública y enfermedad de chagas: El caso de la provincia de Santiago del Estero, argentina. Comunidad y Salud, 11(2), 27-37.

Mandrini, M. R., Cejas, N., y Bazán, A. M. (2018). Erradicación de ranchos, ¿Erradicación de saberes?: Reflexiones sobre la región noroeste de la provincia de Córdoba, Argentina. Anales del Instituto de Arte Americano 48(1), 83-94. Disponible en: https:// ri.conicet.gov.ar/handle/11336/92596

Ministerio Desarrollo Social Santiago del Estero (2021). Re: Vivienda Social. Subsecretaria de Promoción Humana. Disponible en: http://www.mdssde.gob.ar/index.php/ planos/

MOCASE, \& ESfÀ. (2005). El rancho Santiagueño. Testigo de la identidad campesina. Barcelona.

Olivarez, J. E., y Fonzo Bolañez, C. Y. (2021). Territorialidades emergentes: entre lo disponible y lo posible. El caso de la UPPSAN, Santiago del Estero, Argentina. Trabajo y Sociedad, 37(XXII), 99-116.

Passeri, S. (2008). Políticas públicas de vivienda y déficit habitacional en la provincia de Santiago del Estero. Cifra, 3, 97-129. Disonible en: https://fhu.unse.edu.ar/carreras/ rcifra/06passeri.pdf

Paz, R., Lipshitz, H., Zerda, H. R., y Tiedeman, J. (2015). Estructura agraria, áreas de concentración de la agricultura familiar y procesos de expansión de la frontera agropecuaria en Santiago del Estero, Argentina. Revista NERA, 18(27), 259-279.

Sack, R. D. (1986). La territorialidad humana. Su teoría y la historia. Cambridge studies in historical geography (Vol. 7). CAMBRIDGE.

Sánchez Quintanar, C., \& Jiménes Rosas, E. O. (2015). La Vivienda Rural. Su complejidad y estudio desde diversas disciplinas. Luna Azul, (30), 174-196. Disponible en: https://www.redalyc.org/ pdf/3217/321727232011.pdf

\section{Notas}

1 Arquitecto (UNT). Becario Doctoral CONICET. Doctorando en Arquitectura (UNT). Integrante del equipo de Sociología Rural del INDES (FHCSyS/ UNSE CONICET). Facilitador en la Diplomatura 
en Agricultura Familiar y Transformaciones territoriales

2 Arquitecto e Investigador Adjunto CONICET. Integrante del Instituto de Investigaciones Territoriales y Tecnológicas para la Producción del Hábitat, Facultad de Arquitectura y Urbanismo, Universidad Nacional de Tucumán / CONICET. 